\title{
Blood Pressure Control and Heart Rate: Effectiveness Brief Hypnotic Induction Methods on Adults
}

\author{
Ayu Kurnia $\mathrm{S}^{1}$, Dian Veronika Sakti Kaloeti ${ }^{2 *}$, Kwartarini Wahyu Yuniarti ${ }^{3}$, \\ Nanda Erfani Saputri ${ }^{4}$
}

${ }^{1}$ Master of Psychology, Fakultas Psikologi, Universitas Diponegoro, Semarang, Indonesia

${ }^{2}$ Family Empowerment Center, Fakultas Psikologi, Universitas Diponegoro, Semarang, Indonesia

${ }^{3}$ Faculty of Psychology, Gadjah Mada University, Semarang, Indonesia

${ }^{4}$ Fakultas Psikologi, Universitas Diponegoro, Semarang, Indonesia

*Corresponding author. Email: dvs.kaloeti@live.undip.ac.id

\begin{abstract}
Hypertension is a major public health problem and the key risk factor for cardiovascular diseases in adults. This study aims to determine the effect of brief hypnotic induction methods on lowering hypertension in adults. The intervention method utilized in this study involved brief hypnotic induction. This study used a digital tension meter to measure blood pressure and an oximeter to measure heart rate before and after the induction. The results indicated that all participants $(\mathrm{N}=37)$ decreased their systolic blood pressure $(\mathrm{p}=0.008 ; \mathrm{p}<0,05)$ and diastolic blood pressure $(p=0.041 ; p<0,05)$ after intervention. In addition, heart rate also decreased $(p=0.000 ; p<0,05)$ from baseline to intervention. The changes before and after induction between systolic blood pressure, diastolic blood pressure, and heart rate were $4.730 \mathrm{mmHg}, 3.676 \mathrm{mmHg}, 7,270 \mathrm{mmHg}$ respectively. This study concludes that brief hypnotic induction methods have effective to decrease blood pressure and heart rate in adults with hypertension. Further, the results provide an alternative brief intervention for clinical psychologists and health workers as an effort to reduce adult hypertension.
\end{abstract}

Keywords: Blood Pressure, Brief Hypnotic Induction Methods, Heart Rate.

\section{INTRODUCTION}

Hypertension is one of the health problems in adults in Indonesia that needs attention. Based on Basic Health Research conducted by the Ministry of Health of the Republic of Indonesia in 2018, several chronic diseases experienced by Indonesians such as hypertension, asthma, chronic obstructive pulmonary disease, cancer, diabetes mellitus, coronary heart disease, heart failure, stroke, chronic kidney failure, stones kidney, and joint disease [1]. Moreover, 63.2\% of hypertension cases in Indonesia was undiagnosed [2]. Hypertension is a "silent disease" that causes death in Indonesia [3]. High cardiovascular risk generally occurs in Indonesian adults who are over 40 years old and have a relatively low level of preventive care [4]. Hypertension is the main cause of increased cardiovascular disease, especially in high-risk populations (e.g. diabetes minority populations, the elderly, and people with stroke) [5]. This is in line with [6] that individuals with hypertension can coexist with cardiovascular disease, diabetes, and kidney disorders. Another study conducted by [7] in several countries, namely China, Ghana, India, Mexico, Russia, and South Africa, shows that hypertension has a strong relationship with cardiovascular disease.

Several techniques to reduce hypertension have been studied in various studies [8] conducted an 85 articles systematic review on tailored intervention techniques, namely individual interventions that adjust interventions with individual specific needs, abilities, and preferences. This technique is effective for lowering blood pressure in the long term [8]. Another technique is blood pressure telemonitoring 
with a smartphone [9]. Blood pressure telemonitoring techniques combined with self-care support are considered effective in reducing blood pressure. Besides, a study on 120 participants with hypertension in China used motivational interviewing counselling as an intervention in hypertension treatment [10]. The results of this study indicate a positive effect of motivational interviewing in improving medication adherence and blood pressure control in hypertensive patients.

The brief hypnotic induction is one of the interventions that considered effective in reducing hypertension in adults. A study on 30 participants with hypertension showed that hypnosis techniques were effective in lowering blood pressure not only in the short term but also in the long term [11]. Hypnotic induction has various positive impacts, including increased well-being, self-control, sleep quality, and life satisfaction [12]. The phenomenon of hypnosis has an impressive influence on humans due to the strong impact of words on thoughts, feelings, and actions, and suggestions can be used to compose or rearrange the imagination, experience, and individual narratives about the world and oneself [13]. However, on the other hand, there was some debate about hypnosis techniques. Hypnosis is often described as mystical [14]. One of the causes of this misunderstanding is due to the production of media so that the standard in using the hypnotic induction technique needs to be considered. Also, the effectiveness of hypnosis really depends on the relationship between the clinician and the client involved [15]. Based on this explanation, discussion about the effectiveness of brief induction is a topic that needs to be developed. This study aims to determine the effect of brief hypnotic induction methods on lowering adults with hypertension condition.

\section{METHOD}

\subsection{Participants}

Participants in this study were 37 individuals who registered through online media announcements. The sampling technique used purposive sampling, with the participant inclusion criteria, namely: (1) an adult (> 18 years old) (2) having hypertension (3) willing to take part in a research program proven by informed consent. Furthermore, registered participants were invited to attend an offline meeting to validate the study inclusion criteria and sign the informed consent provided.

\subsection{Measurements}

This study used three instruments, namely the induction script used in the intervention process, a digital tension meter to measure blood pressure, and an oximeter to calculate the heart rate before and after induction was given. The induction script made by researcher teams based on the ladder technique which consists of two stages to present an atmosphere of relaxation to the participants [16] (see Table 1).

Table 1. Stairs technique in making induction script

\begin{tabular}{|c|c|}
\hline Activity & Detail \\
\hline \multicolumn{2}{|c|}{ First Stage (Hypnotic induction) } \\
\hline $\begin{array}{l}\text { Down the } \\
\text { twenty stairs }\end{array}$ & $\begin{array}{l}\text { Describes the journey atmosphere of } \\
\text { down the twenty stairs and lived } \\
\text { each step. }\end{array}$ \\
\hline $\begin{array}{l}\text { Get into a } \\
\text { comfortable } \\
\text { position }\end{array}$ & $\begin{array}{l}\text { Find a very comfortable place, then } \\
\text { sit in that place. }\end{array}$ \\
\hline $\begin{array}{l}\text { Focus on one } \\
\text { point }\end{array}$ & $\begin{array}{l}\text { Participants are instructed to pay } \\
\text { attention to relaxed things, such as a } \\
\text { comfortable beach, or the sensation } \\
\text { of floating in the water. Participants } \\
\text { are instructed to practice breathing } \\
\text { techniques. }\end{array}$ \\
\hline \multicolumn{2}{|c|}{$\begin{array}{l}\text { Second Stage (Hypnotic regression and trigger } \\
\text { control) }\end{array}$} \\
\hline $\begin{array}{l}\text { Remembering } \\
\text { experience }\end{array}$ & $\begin{array}{l}\text { Recalling uncomfortable polysensory } \\
\text { experiences. In addition, participants } \\
\text { are instructed to express it, through } \\
\text { auditory, smell, taste, and other } \\
\text { expressions. }\end{array}$ \\
\hline Move on & $\begin{array}{l}\text { Participants are instructed to look at } \\
\text { themselves, and get up from their } \\
\text { seats as a symbol of rising from the } \\
\text { negative feelings }\end{array}$ \\
\hline Up the stairs & $\begin{array}{l}\text { Participants were instructed to up the } \\
\text { stairs and slowly exit the trance with } \\
\text { a more refreshed state. }\end{array}$ \\
\hline
\end{tabular}




\subsection{Procedure}

There are 5 stages carried out in this research. The first stage was the preparation stage. Research participants attended the implementation of the intervention according to a predetermined schedule. In addition, hypnosis training procedures are given in a small, quiet, and comfortable place [17]. Researchers prepared a special soundproof room to carry out the induction process. The second stage was the Pre-Induction Activity (Stage 1). Participants are directed to fill in basic demographic information (gender, age) and sign an agreement, then the experimenter explains the experimental procedure that participants will follow hypnotic induction relaxation followed by a response questionnaire. Before the induction process was given, the participant's heart rate and blood pressure were calculated. Participants are directed to sit in a comfortable position. In particular, participants were instructed to take a deep breath and release it slowly to bring calm, then progressive muscle relaxation (PMR) is given. The next stage was a brief hypnotic induction that is done by reading the induction script accompanied by relaxation instruments. The researcher was assisted by two students who had been trained to make observations on research participants during the induction. In the last stage, participants are allowed to discuss their experiences during the induction process and are not allowed to discuss the procedures that have been carried out with other colleagues. In addition, the participant's heart rate and blood pressure were calculated.

\subsection{Data Analysis}

Data analysis in this study used IBM SPSS (Statistical Products and Solution Services) Statistics 25 . Hypothesis testing was performed using bivariate analysis (paired sample t-test) to test for differences in systolic blood pressure, diastolic blood pressure, and heart-rate before and after the study was performed. induction. Before data analysis is given, a normality test is first performed to see the distribution of research data using the Kolmogorov-Smirnov test.

\section{RESULTS}

\subsection{Demographic Participants}

Based on participant's characteristics data shows that a total of 37 participant's responses were collected, with more than half are women $(56,7 \%)$ and most of the participant's age was between 18-20 years $(43,2 \%)$. A more detailed description of the demographic participants can be seen at Table 2 .

Table 2. Participants Demography

\begin{tabular}{|l|c|c|}
\hline \multirow{2}{*}{ Category } & \multicolumn{2}{l|}{ Total } \\
\cline { 2 - 3 } \multicolumn{2}{|l|}{ Quantity } & $\%$ \\
\hline Gender & 16 & $43,2 \%$ \\
\hline Man & 21 & $56,7 \%$ \\
\hline Woman & 16 & $43,2 \%$ \\
\hline Age & 10 & $27 \%$ \\
\hline $18-20$ years old & 7 & $18,9 \%$ \\
\hline $21-23$ years old & 4 & $10,8 \%$ \\
\hline $24-27$ years old & & \\
\hline$>28$ years old &
\end{tabular}

\subsection{Hypothesis Test}

Before testing the hypothesis, the researcher first tests the normality of the data. The results of the data normality test showed that the systolic and diastolic blood pressures as well as the heart-rate before and after the induction were normally distributed ( $p$ > 0.05). More detailed normality test results can be seen in Table 3.

Table 3. Systolic and Diastolic Blood Pressure Normality Test and Heart-rate Before and After Induction

\begin{tabular}{|l|l|l|l|l|l|}
\hline Variable & Mean & $\begin{array}{l}\text { Standard } \\
\text { Deviation }\end{array}$ & $\mathrm{N}$ & $\begin{array}{c}p \\
\text { value }\end{array}$ & Note \\
\hline TDS pre & 120,65 & 17,414 & 37 & 0,796 & Normal \\
\hline TDSpost & 115,92 & 13,274 & 37 & 0,669 & Normal \\
\hline TDD pre & 79,84 & 11,546 & 37 & 0,533 & Normal \\
\hline $\begin{array}{l}\text { TDD } \\
\text { post }\end{array}$ & 76,16 & 10,071 & 37 & 0,999 & Normal \\
\hline HR pre & 86,16 & 15,851 & 37 & 0,655 & Normal \\
\hline HR post & 78,89 & 12,545 & 37 & 0,106 & Normal \\
\hline
\end{tabular}


Based on the results of the bivariate analysis test, it showed that there was a decrease in systolic blood pressure $(\mathrm{p}=0.008, \mathrm{p}<0.05)$, diastolic blood pressure $(\mathrm{p}=0.041, \mathrm{p}<0.05)$ and heart-rate $(\mathrm{p}=$ $0.000, \mathrm{p}<0.05)$ (Table 2). In addition, the mean systolic blood pressure before induction was 120.65 $\mathrm{mmHg}$ and after induction was $115.92 \mathrm{mmHg}$ (a decrease of $4.730 \mathrm{mmHg}$ ). Further, the average diastolic blood pressure before induction was 79.84 $\mathrm{mmHg}$ and after induction was $76.16 \mathrm{mmHg}$ (a decrease of $3.676 \mathrm{mmHg}$ ). The average heart rate also decreased by 86.16 / minute before induction, to 78.89 / minute after induction (a decrease of 7,270 $\mathrm{mmHg})$.

Table 4. Hypothesis test results before and after induction

\begin{tabular}{|c|c|c|c|c|c|c|}
\hline & $\mathrm{N}$ & Mean & $\begin{array}{l}\text { Std. } \\
\text { Deviation }\end{array}$ & Correlation & $\mathrm{t}$ & Sig. \\
\hline 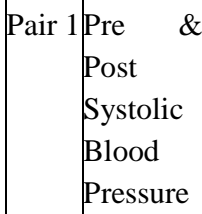 & 37 & 4.730 & 16.724 & .432 & 1.720 & .008 \\
\hline \begin{tabular}{|c|c|} 
Pair 2 & Pre \& \\
& Post \\
& Systolic \\
& Blood \\
& Pressure
\end{tabular} & 37 & 3.676 & 12.503 & .337 & 1.788 & .041 \\
\hline 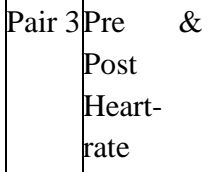 & 37 & 7.270 & 10.715 & .739 & 4.127 & .000 \\
\hline
\end{tabular}

Furthermore, the standard deviation of systolic blood pressure before induction was $17.414 \mathrm{mmHg}$. Meanwhile, the standard deviation of systolic blood pressure after induction was $13.274 \mathrm{mmHg}$. On the other hand, the standard deviation of diastolic blood pressure before induction is $11.546 \mathrm{mmHg}$. Meanwhile, the standard deviation of diastolic blood pressure after induction was $10.071 \mathrm{mmHg}$ (Graph $1)$.

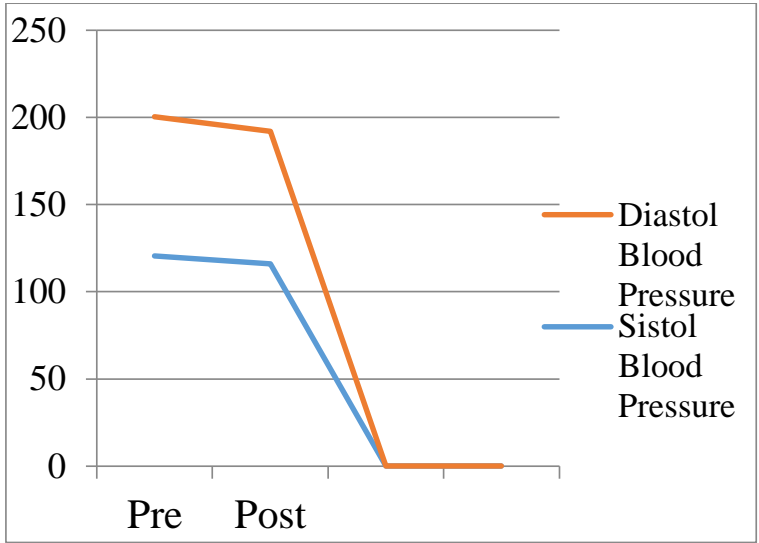

Graph 1. The changes in mean blood pressure before and after induction

In addition, the standard deviation of the heart rate before induction was 15.851 / minute, while the standard deviation of the heart rate after induction was 2.545 / minute (Graph 2).

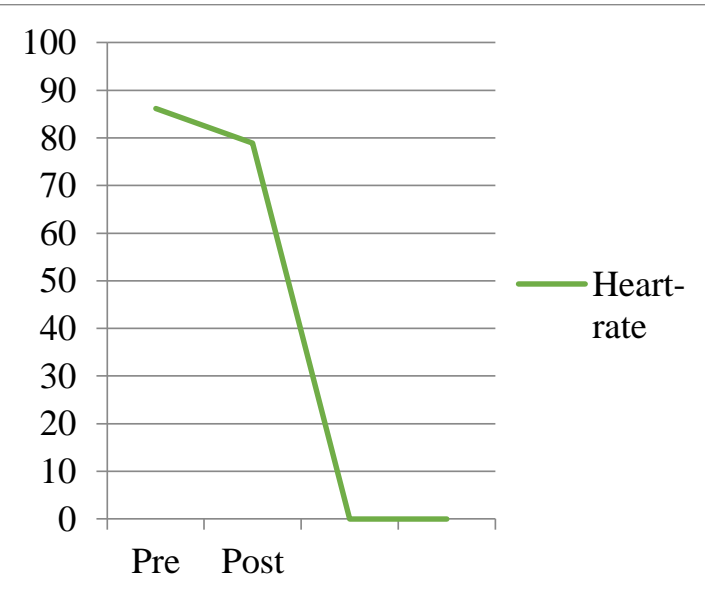

Graph 2. The changes in Average Heart-rate Before and After Induction

\subsection{Discussion}

The findings in this study indicate that brief hypnotic induction can reduce blood pressure and heart rate in adults with hypertension. This is in line with the findings of previous studies which show that hypnosis techniques can lower blood pressure, not only in the short term but in the long term [11]. Apart from lowering blood pressure, this technique can simultaneously lower the heart rate. A study on 22,093 participants showed that $29.2 \%$ of participants who had a high cardiovascular risk tended to have hypertension, coronary heart disease, stroke, and 
other atherosclerotic diseases [4]. On the other hand, brief hypnotic induction proven to be effective in treating various cases including chronic pain [18] cancer treatment procedures $[19,20]$, and some skin disorders [21] [22].

In this study, $85 \%$ of research subjects reported experiencing a positive impact after participating in the program, namely the effect of relaxing, feeling happier, and being inspired to present a calm atmosphere at home. This is in line with previous research which shows that treatment using hypnotic induction techniques has various positive impacts, including improvements in well-being, self-control, sleep quality, and life satisfaction [12].

Furthermore, the previous research stated that several things need to be considered in the implementation of hypnotic induction. The relationship between clinician and client greatly influences the effectiveness of hypnosis [15]. However, in the implementation of this study, there were no longer special sessions with clients to build report cards, but the space provided and giving clear instructions to clients were important factors in the success of the intervention. This is in line with research conducted by [12] which states that techniques and giving clear directions to clients are more influential on the success of the intervention than efforts to build relationships between clinicians and clients. Therefore, in future studies, this technique can be developed in the form of an audio recording so that clients can conduct self-help intervention in their respective homes.

In summary, the brief hypnotic induction methods are an effective intervention to decreased blood pressure and heart rate in adults with hypertension. Also, the evidence suggested that hypnosis affects emotions, thoughts, and perceptions. On the other hand, the results provide an alternative brief intervention for clinical psychologists and health workers as an effort to reduce adult hypertension. Future research can develop a brief hypnotic induction with internet-based intervention so that self-help intervention can be implemented by adults and conduct longitudinal studies to see the long-term effects of brief hypnosis.

\section{REFERENCES}

[1] Kementerian Kesehatan Republik Indonesia. Indonesia health sector review. 2014 [cited 15
Jan 20]. Available from: https://reliefweb.int/sites/reliefweb.int/files/reso urces/NonAsciiFileName0_1.pdf

[2] Kementerian Kesehatan Republik Indonesia. Hasil utama Riskesdas 2018. 2019[cited 15 Jan 20]. Available from: https://kesmas.kemkes.go.id/assets/upload/dir_5 19d41d8cd98f00/files/Hasil-riskesdas-

2018_1274.pdf

[3] D. Rahmatika. The correlation of emotional support and elderly diet compliance with hypertension. Ind. J. Pub. Health 14(2) (2019) 256-261.

DOI: 10.20473/ijph.vl14il.2019.256-261.

[4] A. Maharani, Sujarwoto, D. Praveen, D. Oceandy, G. Tampubolon, A. Patel. Cardiovascular disease risk factor prevalence and estimated 10-year cardiovascular risk scores in Indonesia: The SMARThealth Extend study. PLOS ONE. 2019; 14(4): e0215219. DOI: 10.1371/journal.pone.0215219.

[5] S.I. McFarlane, G. Jean-Louis, F. Zizi, A.T. Whaley-Connell, O. Ogedegbe, A.N. Makaryus, I. Marai. Hypertension in the highcardiovascular-risk populations. Int. J. Hypertens. $2011 . \quad$ DOI: 10.4061/2011/746369.

[6] C.Y. Wu, H.Y. Hu, Y.J. Chou, N. Huang, Y.C. Chou, C.P. Li. High blood pressure and allcause and cardiovascular disease mortalities in community-dwelling older adults. Medicine. 94(47) (2015) e2160. DOI: $10.1097 \% 2 F M D .0000000000002160$

[7] Y. Ruan, Y. Guo, Y. Zheng, Z. Huang, S. Sun, P. Kowal, F. Wu. Cardiovascular disease (CVD) and associated risk factors among older adults in six low-and middle-income countries: results from SAGE Wave 1. BMC Public Health. 8 (2018) 778. DOI: 10.1186/s12889-018-5653-9

[8] K. Radhakrishnan. The efficacy of tailored interventions for self - management outcomes of type 2 diabetes, hypertension or heart disease: a systematic review. J. Adv. Nurs. 68(3) (2011) 496-510

[9] A.G. Logan, M.J.Irvine, W.J. McIsaac, A. Tisler, P.G. Rossos, D.S.A. Easty, J.A. Cafazzo. 
Effect of home blood pressure telemonitoring with self-care support on uncontrolled systolic hypertension in diabetics. Hypertension. 2012; 60(1): 51-57. DOI: 10.1161/HYPERTENSIONAHA.111.188409

[10] C. Ma, Y. Zhou, W. Zhou, C. Huang. Evaluation of the effect of motivational interviewing counselling on hypertension care. Patient Educ. Couns. 95(2) (2014) 231237. DOI: 10.1016/j.pec.2014.01.011

[11] M.C. Gay. Effectiveness of hypnosis in reducing mild essential hypertension: a one-year follow-up. Int J Clin Exp Hypn. 55(1) (2007) 67-83.

DOI: $10.1080 / 00207140600995893$.

[12] M.P. Jensen, D.R. Patterson. Hypnotic approaches for chronic pain management: clinical implications of recent research findings. Am Psychol 69(2) (2014) 167-177. DOI: 10.1037/a0035644.

[13] S.J. Lynn, J.R. Laurence, I. Kirsch. Hypnosis, suggestion, and suggestibility: An integrative model. Am J Clin Hypn 57(3) (2015) 314-329. DOI: $10.1080 / 00029157.2014 .976783$

[14] D.B. Reid. Hypnotic induction: enhancing trance or mostly myth? Am J Clin Hypn 59(2) (2016) 128-137.

DOI: 10.1080/00029157.2016.1190310.

[15] J. Haley. An interactional explanation of hypnosis. Int J Clin Exp Hypn 63(4) (2015) 422-443.

DOI: $10.1080 / 00207144.2015 .1062696$

[16] D.C. Hammond. Handbook of hypnotic suggestions and metaphors. New York: Norton; 1990.

[17] J.K. Pates, I. Maynard. Effects of hypnosis on flow states and golf performance. Percept. Mot. Ski. 91 (2000) 1057-1075.

[18] T. Adachi, A. Nakae, J. Sasaki. Effects of a hypnotic induction and an unpleasantnessfocused analgesia suggestion on pain catastrophizing to an experimental heat stimulus: a preliminary study. Int J Clin Exp Hypn. 64(4) (2016) 434-55. DOI: $10.1080 / 00207144.2016 .1209039$.
[19] C. Tomé-Pires, J. Miró. Hypnosis for the management of chronic and cancer procedurerelated pain in children. Int $\mathbf{J}$ Clin Exp Hypn. 60(4) (2012) 432-57. DOI: $10.1080 / 00207144.2012 .701092$.

[20] G.H. Montgomery, J.B. Schnur, K. Kravits. Hypnosis for cancer care: over 200 years young. CA: Cancer J Clin 63(1) (2013) 31-44. DOI: 10.3322/caac. 21165 .

[21] P.D. Shenefelt. Mindfulness-Based cognitive hypnotherapy and skin disorders. Am J Clin Hypn 61(1) 34-44. DOI: $10.1080 / 00029157.2017 .1419457$

[22] A.M. Gartner, S.L. Dolan, M.S. Stanford, G.R. Elkins. Hypnosis in the treatment of morgellons disease: a case study. Int J Clin Exp Hypn. 59(2) (2011) 242-249.

DOI: $10.1080 / 00207144.2011 .546263$. 